\title{
Swallowed toothbrush: Case series
}

\author{
S. Kiran, Deepak Gupta, Abhishek Sadalage, Amit Gupte, Abhinav Jain, Akash Shukla
}

Department of Gastroenterology, Seth G.S. Medical College and KEM Hospital, Mumbai, Maharashtra, India

$\begin{array}{ll}\text { Abstract } & \text { Toothbrush swallowing is rare, and most cases are seen in young women with anorexia } \\ \text { nervosa or bulimia or associated with mental retardation or schizophrenia. Prompt removal } \\ \text { is recommended because no cases of spontaneous passage have been reported. There is no } \\ \text { previously reported case series on swallowed toothbrush in mentally normal young men. } \\ \text { Here, we report three cases of swallowed toothbrush found in the esophagus and stomach } \\ \text { on endoscopy. In our case series, successful removal of the toothbrush was done without } \\ \text { endotracheal intubation or over tube, without any complications. To our knowledge, this is the } \\ \text { first documented case series of swallowed toothbrush managed successfully endoscopically. }\end{array}$

\section{Introduction}

Foreign body ingestion is a common emergency, especially in children. ${ }^{[1]}$ Most common foreign bodies in children are coins, but marbles, buttons, batteries, safety, pins, and bottle tops have also been reported. ${ }^{[2-4]}$ In adults, common foreign bodies are fish or chicken bones, dentures, and metallic wires. Foreign bodies except elongated ones which have gone beyond the esophagus usually pass uneventfully through gastrointestinal (GI) tract in $70-80 \%$ cases. Toothbrush ingestion is uncommon but requires prompt medical attention toothbrush is unlikely to pass spontaneously as it would not be able to negotiate "c" loop of duodenum because of its long length. ${ }^{[5]}$

\section{Case Report}

We encountered three cases of accidental toothbrush ingestion. These cases occurred over the period October 2013-May 2014 and involved three men all in their $3^{\text {rd }}$ decade of life. All three patients presented to the Emergency

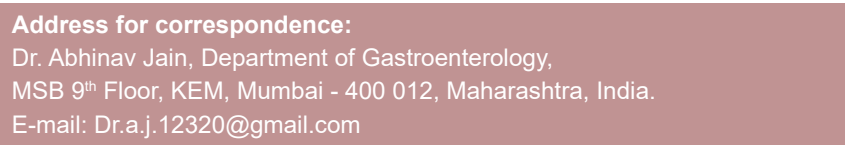

\begin{tabular}{|l|c|}
\hline \multicolumn{2}{|c|}{ Access this article online } \\
\hline \multirow{2}{*}{$\begin{array}{l}\text { Website: } \\
\text { www.jdeonline.in }\end{array}$} & Quick Response Code \\
\hline \multirow{2}{*}{$\begin{array}{l}\text { DOI: } \\
\text { 10.4103/0976-5042.189158 }\end{array}$} & \\
\hline
\end{tabular}

Department with a history of accidental swallowing of the toothbrush when trying to clean the posterior part of the tongue with tongue cleaner on the brush head. Two patients had a history of acid peptic disease for which they were doing repeated self-induced vomiting especially in the morning, which is inappropriate but commonly performed maneuver in India. None had any pain or vomiting. They had no previous history of foreign body ingestion and no comorbid conditions.

In the first case, computed tomography abdomen revealed toothbrush in the stomach [Figure 1]. Endoscopic retrieval of the toothbrush was undertaken in the endoscopy room. In all three cases, endotracheal intubation was not done; mild sedation was given with midazolam. An upper gastrointestinal endoscopy was done and this showed the toothbrush in the esophagus [Figures 2 and 3] in two cases and in the stomach in the third case. The brush was snared, and withdrawn en masse without over tube to the level of cricopharyngeus and then, gently pulled out while asking the patient to do swallowing movements simultaneously. Relook endoscopy was undertaken to confirm the safety of the procedure. The patients were discharged two hours later in possession of the offending toothbrush. Future attempts to use the tongue cleaner were discouraged.

This is an open access article distributed under the terms of the Creative Commons Attribution-NonCommercial-ShareAlike 3.0 License, which allows others to remix, tweak, and build upon the work non-commercially, as long as the author is credited and the new creations are licensed under the identical terms.

For reprints contact: reprints@medknow.com

How to cite this article: Kiran S, Gupta D, Sadalage A, Gupte A, Jain A, Shukla A. Swallowed toothbrush: Case series. J Dig Endosc 2016;7:77-9. 


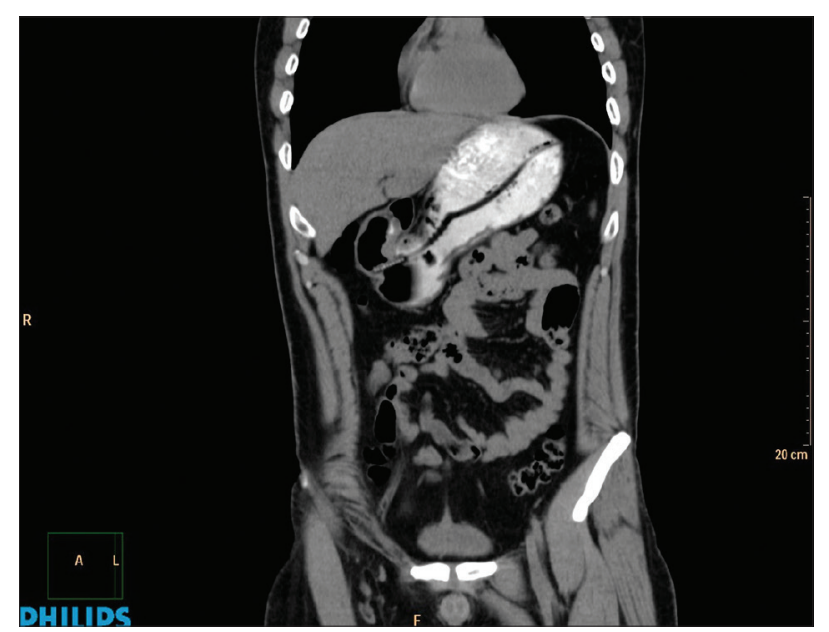

Figure 1: Oblique coronal CT reveals the full length of a tooth brush swallowed by the patient. Notice the bristles of the toothbrush near the pylorus and its curved handle directed towards the body of the stomach

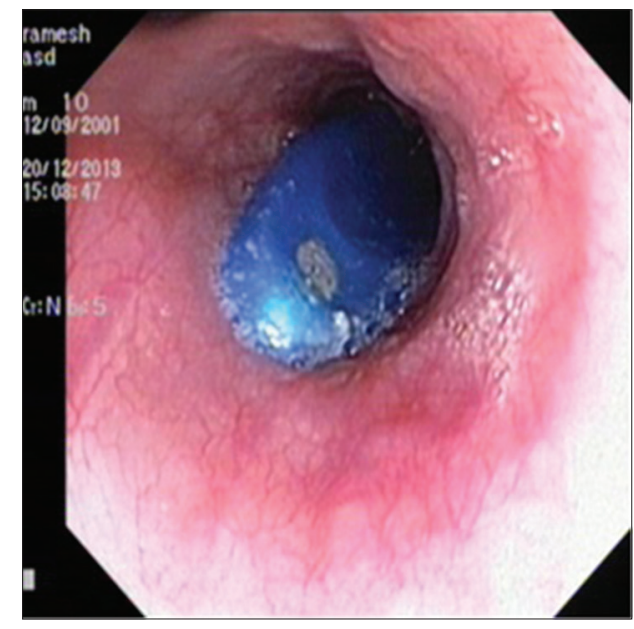

Figure 2: End of toothbrush in esophagus

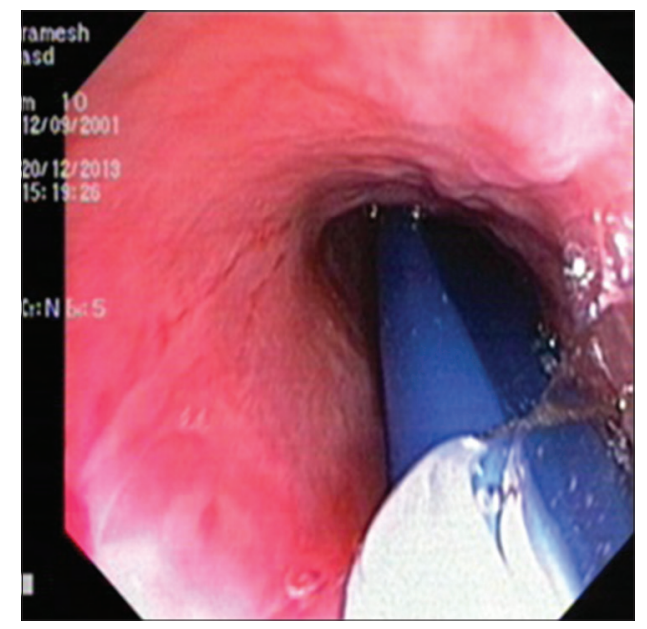

Figure 3: Toothbrush being removed

\section{Discussion}

Ingestion of a foreign body is commonly encountered among children, adults with intellectual impairment, psychiatric illness or alcoholism, and dental prosthetic-wearing elderly subjects. ${ }^{[5-7]}$ However, toothbrush swallowing is rare, with only approximately forty reported cases..$^{[5]}$

In this case series, the toothbrush was removed during gastroscopy using snare. To the best of our knowledge, this is the first case series of successful endoscopic removal of swallowed toothbrush. Precautions needed to avoid complications of the procedure are team experienced in endoscopic intervention, endotracheal intubation tray, anesthetist, and surgeons stand by, preferably removal should be performed in the OT with facilities for laparotomy or laparoscopic intervention in cases of failed endoscopic removal. Accessories required are polypectomy snare, Roth Net, magills forceps (adult size), endotracheal intubation tray.

Special manouvers needed during removal of the toothbrush from the GI tract are that it should be held at a point as close to the end as possible on the handle of the toothbrush with adequate grip on the toothbrush so as to avoid it getting impacted at gastroesophageal junction and upper esophageal sphincter, also this prevents it going into the nasopharynx once it passes the upper esophageal sphincter into the oropharynx while negotiating the turn into the oral cavity. We encountered this problem in the first case, wherein the toothbrush entered into the nasopharynx, and we pushed it back slightly into the upper esophagus before using a magills forceps to remove it under direct vision using a laryngoscope. Furthermore, as the toothbrush reaches the oropharynx the patients head can be put in extension position before pulling out the toothbrush to avoid injury to the oropharynx. Other important manouver is at the upper esophageal sphincter, asking the patient do swallowing movements continuously will help relax the sphincter aiding in easy removal, but this is possible only when the patient is under conscious sedation. It is important that the long axis of the toothbrush is parallel to the esophagus during extraction to avoid injury.

Ertan et al. ${ }^{[8]}$ reported the first case of successful removal of a swallowed toothbrush. Other authors found the endoscopic approach unsuccessful due to the size and shape of the ingested toothbrush. ${ }^{[9,10]}$ Objects longer than $6-10 \mathrm{~cm}$ have difficulty in passing the duodenal sweep. ${ }^{[1]}$ In addition; esophageal perforation during the endoscopic extraction of a toothbrush has been reported..$^{[7]}$ In one case report, the toothbrush passed through the pylorus, duodenal loop, ileocecal valve, and perforated the proximal transverse colon and then penetrated the liver. ${ }^{[12]}$ The first reported death from a toothbrush occurred in 1889 as a result of gastric perforation 3 days postingestion. ${ }^{[13]}$ In another reported case, the toothbrush penetrated the oropharyngeal region of a young boy, a broken part wedged close to the carotid artery. ${ }^{[14]}$ In a review of 31 cases of toothbrush ingestion, no episodes of spontaneous passage were reported. Complications related to pressure necrosis, including gastritis, mucosal tears, and perforations, occurred in several of these cases. ${ }^{[5]}$ 
In our case series, successful removal of toothbrush from esophagus and stomach without endotracheal intubation or over tube, without any complications was achieved. Furthermore, our case series was unusual because all were adults without mental abnormality and two of them had the habit of cleaning the posterior part of the tongue with the toothbrush head.

\section{Conclusion}

An ingested toothbrush cannot pass spontaneously through the GI tract. Early removal of the ingested toothbrush is advised to avoid impaction of the toothbrush at the duodenum and to minimize morbidity. Endoscopic removal should be performed by a skilled endoscopist.

\section{Acknowledgement}

We are thankful to Dr. Yashant Aswani, for contributing the CT image.

\section{Financial support and sponsorship}

Nil.

\section{Conflicts of interest}

There are no conflicts of interest.

\section{References}

1. Sanowski RA. Foreign body extraction in the gastrointestinal tract. In:
Sivak MV, editor. Gastroenterological Endoscopy. Philadelphia: W.B. Saunders Co.; 1987. p. 321-31.

2. Webb WA, McDaniel L, Jones L. Foreign bodies of the upper gastrointestinal tract: Current management. South Med J 1984;77:1083-6.

3. Hawkins DB. Removal of blunt foreign bodies from the esophagus. Ann Otol Rhinol Laryngol 1990;99:935-40.

4. Hamilton JK, Polter DE. Gastrointestinal foreign bodies. In: Sleisenger MH, Fordtran JS, editors. Gastrointestinal Disease: Pathophysiology, Diagnosis and Management. Philadelphia: W.B. Saunders Co.; 1993. p. 286-92.

5. Kirk AD, Bowers BA, Moylan JA, Meyers WC. Toothbrush swallowing Arch Surg 1988;123:382-4.

6. Velitchkov NG, Grigorov GI, Losanoff JE, Kjossev KT. Ingested foreign bodies of the gastrointestinal tract: Retrospective analysis of 542 cases. World J Surg 1996;20:1001-5.

7. Selivanov V, Sheldon GF, Cello JP, Crass RA. Management of foreign body ingestion. Ann Surg 1984;199:187-91.

8. Ertan A, Kedia SM, Agrawal NM, Akdamar K. Endoscopic removal of a toothbrush. Gastrointest Endosc 1983;29:144-5.

9. Wilcox DT, Karamanoukian HL, Glick PL. Toothbrush ingestion by bulimics may require laparotomy. J Pediatr Surg 1994;29:1596.

10. Wishner JD, Rogers AM. Laparoscopic removal of a swallowed toothbrush. Surg Endosc 1997;11:472-3.

11. Eisen GM, Baron TH, Dominitz JA, Faigel DO, Goldstein JL, Johanson JF, et al. Guideline for the management of ingested foreign bodies. Gastrointest Endosc 2002;55:802-6.

12. Lee MR, Hwang Y, Kim JH. A case of colohepatic penetration by a swallowed toothbrush. World J Gastroenterol 2006;12:2464-5.

13. Friedenwald AM, Rosenthal LJ. A statistical report of gastrotomies for removal of foreign bodies from the stomach. N Y Med J Phila Med J 1903:110-23.

14. Sasaki T, Toriumi S, Asakage T, Kaga K, Yamaguchi D, Yahagi N. The toothbrush: A rare but potentially life-threatening cause of penetrating oropharyngeal trauma in children. Pediatrics 2006;118:e1284-6. 